\title{
Learning Strategy Use and Speaking Skills in the Indonesian Context
}

\section{Sri Wahyuni, sri.wahyuni@ unigamalang.ac.id, English Department, Faculty of Social and Cultural Sciences, Gajayana University of Malang, Malang, Indonesia}

\begin{abstract}
This study investigates language learning strategies used by Indonesian tertiary students in learning to speak English. The study addresses what learning strategies the students use; what strategy group and individual strategy they favor, and whether speaking skills significantly affect strategy use. This paper reports the quantitative results of a larger mixed-methods study drawing on the questionnaire $(\mathrm{n}=65)$ and students' speaking grades $(n=65)$ obtained from students at the Gajayana University of Malang in Indonesia. The study demonstrates that the students used a wide range of strategies that spread over six strategy groups of Oxford's taxonomy (1990). Advanced and elementary students favored compensation strategies, and intermediate students, metacognitive strategies. As regards individual strategy, advanced students favored 'using a circumlocution or synonym'; intermediate students, 'paying attention'; and elementary students, 'using resources for receiving and sending messages.' The study also shows that speaking skills significantly affected the use of effective strategies only. The paper concludes by discussing implications for theory and practice.
\end{abstract}

Keywords: language learning strategies; learning strategies for speaking skills; speaking skills

\section{INTRODUCTION}

It is generally believed that some learners perform better than others in learning an L2 (second language). This leads to explorations of the effects of individual learner variables on learning outcomes. Researchers (H.B. Altman, 1980; Larsen-Freeman \& Long, 1991; Skehan, 1989) state that learning strategies are among the learner variables that influence learning outcomes. Ellis (2008) claims that learner variables are interrelating to one another. Learning strategies, hence, affect learning outcomes, and at the same time, learning outcomes also affect strategy use. Because strategies have an effect on learning outcomes, and vice versa, research into this matter has proven useful.

In Indonesian EFL (English as a Foreign Language) context, speaking English is still intimidating to some learners. To help these learners change their attitude towards English speaking, which will lead to better learning outcomes, they have to be made aware of the existence of factors like learning strategies. However, little research on this field has been conducted here. Therefore, the present study is important to do.

This study set out to explore the strategic use of Indonesian EFL tertiary students when they learn to speak English. In this paper, I will report on the quantitative part of a larger mixed-method study, drawing on questionnaire $(n=65)$ and students' speaking grades $(n=65)$ obtained from students at Gajayana University of Malang (GUM) in Indonesia, in an effort to understand what strategies they use; what strategy group and individual strategy they favor; and whether speaking skills significantly affect strategy use. 


\section{METHOD}

Participants of this study $(\mathrm{n}=65)$ were EFL English majors at GUM from year 1 to 5. This participants represents $60 \%$ of all students at the Department of English Language and Literature. The students were between 18 and 25 years old and had studied English at school for at least six years before tertiary entry. They had never received explicit overt strategy training.

Based on their average speaking grades, there were 23 students at an advanced level of speaking skills; 36 , intermediate, and six elementary.

This study report draws on the quantitative part of a larger mixed-methods study. I employed a questionnaire and documents of students' speaking grades. The questionnaire was adapted from the Strategy Inventory for Language Learning (SILL) version 7.0 (ESL/EFL) (Oxford, 1990). Thirty-three statements were adopted from the SILL, and six were original. To collect the data on students' speaking skills, I used documents containing the students' speaking grades achieved at GUM.

To analyze the data, I first used descriptive statistics, focusing on the mean, standard deviation, and range. The mean score obtained from the entire questionnaire items, for example, would indicate the students' overall strategy use. Other mean scores, depending on the focus of the examination, indicated the strategy use of specific groups of students, i.e. groups of students on the level of advanced, intermediate, or elementary. Mean scores also indicated what strategy and strategy group the students favored the most and least, in the sense that, based on a certain ranking, the highest mean score indicated the most favored strategy or strategy group, and the lowest mean score indicated the least favored.

Second, I used inferential statistical analysis to answer whether speaking skills significantly affected strategy use, in particular, the one-way Analysis of Variance (ANOVA). This statistical analysis could help to determine whether or not there was a significant difference in strategy use among the three groups of students with various levels of speaking skills. Additionally, the choice of this statistical technique was determined by the intervalscaled data with a normal distribution of the scores (Pallant, 2007).

\section{RESULT}

The analysis of data shows that students with various levels of speaking skills used a wide range of strategies spreading over six strategy groups.

Descriptive statistics of the students' responses to the entire items of the questionnaire show that the overall strategy-use of these three groups of students is medium. The way Oxford (K.R Lee and Rebecca oxford, 2008) interprets mean scores for the Likert-scaled strategy-use items is that $3.50-5.00$ is high use; $2.50-3.49$, medium use; and $1.00-2.49$, low use. The mean score for the advanced students' overall strategy use is 3.20; the intermediate students' strategy uses 3.15; and the elementary students' strategy use 2.81 .

At the level of individual strategy use, 'using a circumlocution or synonym' has the highest mean score, 4.13, for advanced students. 'Paying attention' has the highest mean score, 4.08, which was employed by intermediate students, whilst 'using resources for receiving and sending messages' has the highest mean score, 4.16, which was used by elementary students. Because these strategies have the highest mean scores, they were the strategies the students favored the most. As regards the strategies the students favoured the least, 'Writing a language learning diary' is the strategy with the lowest mean score which was used by advanced and elementary students, with the means 1.86 and 1.50 respectively. 'Representing sounds in memory' has the lowest mean, 2.19 , and was used by intermediate students. 
With regard to strategy groups the students favoured the most, advanced and elementary students favoured the compensation strategy group the most (mean scores are 3.49 and 3.08 respectively), but intermediate students, the metacognitive strategy group (mean score, 3.43). All the three groups of students favored the memory strategy group the least (mean scores are $2.69,2.59$, and 2.38 , respectively).

One way ANOVA was applied to examine whether or not speaking skills significantly affected strategy use. The results show that the $F$ value is $2.047(p=0.138)$. The $p$-value indicates that the null hypothesis stating that there is no difference in strategy use among students with various levels of speaking skills is not rejected. In other words, speaking skills did not significantly affect the students' overall strategy use. However, at the level of the use of each of the strategy groups, speaking skills significantly affected the use of the effective strategy group. The $\mathrm{F}$ value is $3.555(\mathrm{p}=0.035)$; the $\mathrm{p}$-value indicating that students used affective strategies in significantly different ways, depending on their speaking skills level.

Concerning which pair(s) of groups differed from each other, the LSD post hoc test shows that elementary students significantly differed in affective strategy use from intermediate $(\mathrm{p}=0.011)$. Advanced did not significantly differ from both intermediate $(\mathrm{p}=$ $0.296)$ and elementary $(\mathrm{p}=0.060)$.

One of the reasons for the tendency that advanced students favor 'using a circumlocution or synonym' the most and 'writing a language learning diary' the least is that high proficiency allowed these students to use the highly-demanding strategy and, it was hard for them to see the benefit of 'writing a language learning diary' for their learning of speaking. Intermediate students favor 'paying attention' the most probably because their proficiency level caused them to struggle in producing oral L2. Consequently, they seemed to delay their oral production by paying more attention to other people speaking in L2. They would probably apply the learned knowledge from this activity in their oral production later. Elementary students' top preference for 'using resources for receiving and sending messages' may have to do with their struggle in producing oral L2. Due to their low proficiency, they had to use resources, like a dictionary, to prepare sentences they wanted to say. They may also have needed such resources to help them understand other people's oral L2. As regards the least favored 'representing sounds in memory' and 'writing a language learning diary' strategies for the intermediate and elementary students respectively, a credible reason for this to happen is the low contribution of the strategy to the learning of speaking.

There seemed to be a different underlying reason why advanced and elementary students favoured the same group of strategies the most, the compensation strategy group. The advanced students may have used compensation strategies to help them maintain the fluency of their oral L2, but the elementary ones used them to deal with their insufficient speaking competence so that they still could perform some speaking tasks. Intermediate students, in accordance with their focus of learning by delaying the oral L2 production mentioned earlier, may have used metacognitive strategies to organise their learning so that they could proceed to the advanced level.

Statistically, speaking skills significantly affected the use of affective strategies only $(p=0.035)$, with the difference lying between elementary and intermediate $(p=0.011)$. This finding can be compared with finding in a study of strategy use for speaking skills among Filipino EFL high school students conducted by Cabaysa and Baetiong (Cabaysa \& Baetiong, 2010). The study reveals a significant difference in the use of metacognitive strategies. However, unlike theirs, this study revealed a significant difference in the use of affective strategies between elementary and intermediate. Intermediate students showed higher use of affective strategies than elementary, as indicated by the means of 3.11 and 2.44 respectively. Reasons for this diversity of behaviour are open to speculation. One credible interpretation is 
that the intermediate students, with lower proficiency than the advanced students' but with a strong desire to improve, would experience high level of anxiety in learning to speak. To cope with this, they may have used many affective strategies frequently. Unlike the intermediate students, advanced students may not have been very anxious in learning to speak because they were confident in their proficiency. This is indicated by their mean score, 2.94, which is lower than the intermediate students'. It is very likely that the elementary students were the most anxious but they did not know how to manage their anxiety and had only a weak command of the repertoire of strategies, hence they used affective strategies less. Their mean score for this is the lowest, 2.44 .

One pedagogical implication of this interpretation is the need for more intensive strategy training at elementary level, targeting affective factors. However, it seems simple improvement of proficiency is a natural way of increasing confidence. The advanced students reached their state of confidence without particular strategy training in their earlier development. More elementary and intermediate learners should proceed to advanced level, and strategy training will offer them more chances to do so.

\section{CONCLUSION}

Concerning the question of what strategies students use, this study demonstrated the use of strategies at a total number of 39 strategies. Advanced and elementary students favored compensation strategies, and intermediate students, metacognitive strategies. Concerning individual strategy, advanced students favored 'using circumlocution or synonym'; intermediate students, 'paying attention'; and elementary students, 'using resources for receiving and sending messages.'

As regards whether speaking skills significantly affect strategy use, this study demonstrated that speaking skills significantly affected the use of effective strategies only $(p=0.035)$, and the difference occurred between elementary and intermediate $(p=0.011)$.

The findings of this study lead to the implications of theory and practice. To theory, this study contributes to theories on learning strategies regarding knowledge of the relationship between learning strategies and speaking skills. It contributes to previous information on the significant relationship between strategy use and speaking skills. In this way, the study gives worthwhile support to the findings of other studies and helps strengthen the reliability of the findings of those studies.

Concerning practice, the research implications of this study would be for teachers, curriculum developers, and students. For teachers, this study contributes knowledge of the use of learning strategies for the learning of speaking among students. This knowledge would raise their awareness of the need to provide organized, well-informed strategy training that assists students to use the strategies for their maximum learning outcomes.

For curriculum developers, this study contributes a basis for developing a curriculum that accommodates the need for strategy training. They could either provide the training as a separate strand within the course or design specific syllabi that enable teachers to integrate strategy training into teaching materials.

For students, this study contributes an opportunity for strategy use development, in the sense that as the implications for teachers and curriculum developers are put into practice, students will benefit from a proper program of strategy training. 


\section{REFERENCES}

Cabaysa, C. C., \& Baetiong, L. R. (2010). Language learning strategies of students at different levels of speaking proficiency. Education Quarterly, 68(1).

Ellis, R. (2008). The study of second language acquisition (2. ed). Oxford: Oxford, Univ. Press.

H.B. Altman. (1980). Foreign language teaching: Focus on the learner. Oxford: Pergamon Press Ltd.

K.R Lee and Rebecca oxford. (2008). Understanding EFL Learners' Strategy Use and Strategy Awareness. Asian EFL Journal. Retrieved from https://www.researchgate.net/publication/292469592_Understanding_EFL_Learners'_S trategy_Use_and_Strategy_Awareness

Larsen-Freeman, D., \& Long, M. H. (1991). An introduction to second language acquisition research. London; New York: Longman.

Li, D. (2007). Coping with linguistic challenges in UK higher education: the use of strategies by Chinese research students. Language Learning Journal, 35(2), 205-219. https://doi.org/10.1080/09571730701599237

Oxford, R. L. (1990). Language learning strategies: what every teacher should know. New York: Newbury House Publisher.

Pallant, J. (2007). SPSS survival manual: a step by step guide to data analysis using SPSS for Windows (3. ed., [fully rev.]). Maidenhead: Open Univ. Press.

Skehan, P. (1989). Individual differences in second-language learning. London; New York: New York, NY: Edward Arnold; Distributed in the USA by Routledge, Chapman, and Hall.

Weyers, J. R. (2010). Speaking Strategies: Meeting NCATE Oral Proficiency Standards. Foreign Language Annals, 43(3), 384-394. https://doi.org/10.1111/j.19449720.2010.01089.x. 